\title{
Ranking Motivational Factors of Teachers in Urmia Using SAW Method (2011)
}

\author{
Fariba Azizzadeh ${ }^{1}$ and Alireza Shirvani ${ }^{2}$ and Rasool Sarihi Sfestani ${ }^{3}$ \\ ${ }^{1}$ (Corresponding author) Islamic Azad University, Department of Management, Science \\ and Research Branch, Isfahan, Iran \\ ${ }^{2}$ Islamic Azad University, Department of Management, Science and Research Branch, \\ Isfahan, Iran \\ ${ }^{3}$ Islamic Azad University, Department of Management, Science and Research Branch, \\ Isfahan, Iran
}

\begin{abstract}
Objective: The aim of this study is to rank the motivational factors of teachers that work as private sector employees in schools district 1 in Urmia. This research was done in 2011.
\end{abstract}

Method: The study population included 30 people and the data was analyzed through SAW method. Reliability coefficient of 0.977 was estimated by using Cronbach's alpha and for this it was used SPSS software.

Results: highest credit rating among social interactions factors relate to credibility and reputation and lowest one was protection of social status. The highest and lowest scores among the organizational culture related to teachers' good activity and students' interest. Interest to working outside the home has the highest score among skill factors and mastery of the subject has the minimum score. The degree of competition among teachers with different fields of university education allocated higher score than teachers with same field of education.

\section{KEYWORDS}

Motivation, Ranking Motivational Factors, SAW Method, Teachers

\section{INTRODUCTION}

Creating incentives for greater effort towards organizational objectives has always been a concern of managers. In this regard, various theories have been given as well as various incentive programs. Management is trying to increase employee motivation by applying these theories and implementations of motivation programs. Motivation is one of the factors that drive the performance of the organization.

Teachers as employees who are very influential in the country's future, as people are the key to the future of any country. Motivations of the teachers also have been in the attention of the training system and also parents of students. So the recognizing of these motivations is in public attention. Identifying the motivational factors would be useful in determining maximum capacity of teachers in school and whole country. Thus this study aimed to determine the motivation 
International Journal of Managing Value and Supply Chains (IJMVSC) Vol.5, No. 1, March 2014

factors based on the situations and teachers' specific job properties and then ranking the factors using Simple-additive-weighting (SAW) method.

\section{RESEARCH LITERATURE}

According to researches several factors are affecting employee motivation. Akhundi Bunab et al. (2011) say that if managers have more internal control they will have more positive impact on their staff. It can be said that the more external control of the organization managers lead to the more reduction of its employees' motivation [2].

Ameri (2009) argued human relations climate in the organization and participation in decisionmaking have a positive relation with job motivation [20]. Bakhtiari et al. (2009) in their study determined that an inverse correlation exists between emotional exhaustion and motivation. The increased compensation, improved working conditions, interrelationships, and security, thereby increase the efficiency of the result [3].

Shafizadeh (2002) examined 4 variables that include personal characteristics, job characteristics, workplace characteristics and features of the external environment among sport teachers. He also notes that a significant relation exist between motivation and education. But he mentioned that work experience does not affect the amount of Job motivation [21].

Farhangi et al. in 2006 stated employees believe that relationship between interpersonal and intrapersonal are effective in their work. But they will not alter the relationship between hero and the person's motivation. The relationship between interpersonal includes social dimensions of life and intrapersonal involve ecological dimensions of life. Motivational process is more external and staffs believe that work life is different from spiritual life [4].

Another study which was conducted in Tehran among education consultants shows that significant positive correlations exist between the organizational culture and job motivation. Also Women Trip Advisor had higher levels of motivation and organizational culture and as a result, greater degree of flexibility, employee autonomy, creativity and initiative in working place increase the level of motivation [5]. Radafshar (2010) mentioned that factors such as weather conditions, use of credits, sports clubs and leisure centers, proper sanitation, and working in the private sector and having an adequate financial resources have a significant influence on motivation [17]. Ostvar et al. survey in 2003 shows that the hierarchy of needs from the perspective of managers and employees have a good attunement. Also the motivation of employees and managers from the perspective of a difference is not observed. Managers and employees mentioned the respect and the dignity as the most important needs [15]. But Kajbaf and colleagues demonstrated that significant differences exist in motivational factors in terms of employees and supervisors. Although the biological needs of the staff were mentioned, the need to respect the community was in priority. And it was the most important need against what is believed to be supervisors. This research shows that physiological needs are important in view of supervisors. While employees posed need for growing as the most critical needs [9].

Another study shows that having a definite goal can develop the employees' motivation. Also training programs is a factor for determination [7]. Mahmoudi and Poukazem (2007) stated that the most and the least important factors among the internal factors of motivation as the job identity (52\%) and responsibility (34\%). Among the external factors of motivation, supervision 
International Journal of Managing Value and Supply Chains (IJMVSC) Vol.5, No. 1, March 2014

and monitoring (51\%) were the most important factor, and payroll (29\%) was the least important one. Results of this research suggest that internal motivation factors are more important than extrinsic factors [13]. Ejeyee et al shows that four styles of Motivation include empathy, conformity, objectivity, and the other-base were the key aspects of the stronger predictors of job performance [1].

In other research, the need for respect got the highest score among the motivation factors. The needs for physiologic needs of women were greater than men [10]. Pourhadi et al. (2009) show that a relation exists between aging and sex with motivation potential [16]. In another ranking of motivational factors among the Oil Company Products, the factors of non-financial extrinsic rewards, extrinsic rewards and financial rewards and in the end the internal (intrinsic) incentives have the greatest impact on increasing the motivation [11]. Rao (2006) in his research measures the production of urea and nitrogen. Then he implemented group's motivation in the organization and ultimately measures productivity again [19]. The results of his research show that production level increases by motivation increment. Employee welfare plans (including year-end bonuses, flexible time etc.) have a greater effect on their motivation and have less effect on productivity. Workers with different levels of education have different understanding of the effects of employee welfare. The findings indicate that employee benefit programs are more effective on younger employee [8].

One of the researches in 12 World Bank in Istanbul has been sent to staff on-line questionnaire via email that included all the managers and employees. The number of samples was 116 of 12 banks. According to the results, internal and external motivation influence on employee performance [6]. Another study stated the merit of managers is crucial to increase employee motivation. According to this study, only 23 of the 124 managers used motivational techniques. Managers purposefully assess their motivation skills. And employees believe that loyalty is based on their motivation [12]. Research on 124 directors in Bosnia-Herzegovina confirms these findings. This research suggests that fewer than one in five managers, often apply all the motivation techniques [18].

Motivation is high in the beginning. And it decreases with time. Therefore it is important to managers motivate the members in the final stages [18]. Locus of individuals' control (those who believe they have control over their own destiny) has a significant relation with a sense of satisfaction and motivation. People with internal locus of control believe that they are the master of your own destiny. People with external locus of control are those that believe they have no impact on their future [23]. Emotional stability is recommended to reduce negative emotions. In fact, a positive relation exists between the negative emotion and motivation to learn from mistakes [24].

\section{AIM AND CENTRAL QUESTIONS}

The aim of this study is to rank motivational factors (social, organizational culture, individual factors, and training, competition and skill factors) of teachers. SAW method is used to achieve this goal.

Questions about social interactions include: relationships with parents, respect for students, maintaining social status, credit and approved by the director. The core questions will examine the organizational culture involve: classroom atmosphere, good and bad performance of teachers, 
and student's interests. Personal factors are questions about the remuneration of material prize, educational interest, work ethic and preoccupations outside the classroom. Questions about participation in educational programs, group ranking and discovering training talents were asked to ranking the training factors. Questions of competition factor include the degree of competition among teachers. Questions such as working outdoors, master the skills and experience are questioned to analyze the skill factors. This study is practical and applied research and it identifies and ranks the teachers motivating factors in the District 1 in Urmia. The study population consisted of all teachers (teachers of private sector) in Girls High School that it was 30 persons in District1. For data collection a questionnaire containing 22 questions were used Range of options was divided based on the highest score of 9 to 1. Cronbach's alpha was used to test the reliability of the questionnaires that it was $97 \%$.

Table1. Reliability statistics

\begin{tabular}{|c|c|}
\hline Cronbach's Alpha & N of Items \\
\hline .977 & 22 \\
\hline
\end{tabular}

\section{DATA ANALYSIS}

After collecting the data, normalization of matrix was did. To doing dimensionless it was used Linear Dimensionless. This formula includes:

$\mathrm{N}_{\mathrm{ij}}=\mathrm{r}_{\mathrm{ij}} / \mathrm{r}_{\mathrm{j}}^{*}, \quad \mathrm{r}_{\mathrm{j}}^{*}=\max \mathrm{r}_{\mathrm{ij}}$

In second level to obtain the rank of motivational factors, it was used formula of below:

$\mathrm{E}_{\mathrm{q}}{ }^{*}=\sum \mathrm{w}_{\mathrm{j}} \cdot \mathrm{r}_{\mathrm{ij}} \quad, \quad \mathrm{w}_{\mathrm{j}}=1 / 9=0.111$

Findings from this study suggest that among social interactions agents, the highest rating relates to the credibility and reputation (0.603). The lowest rate relates to the protection of social position (0.38). The rest scores were divided between these two scores. The following table shows the ranking of social interaction.

Table 2 - Ranking of social interaction

\begin{tabular}{|c|c|c|}
\hline incompatibility Factor & $\begin{array}{c}\text { The relative importance } \\
\text { factors }\end{array}$ & Social interaction \\
\hline \multirow{4}{*}{0.015} & 0.603 & Reputation achievement \\
\cline { 2 - 3 } & 0.488 & Relationship with Parents \\
\cline { 2 - 3 } & 0.476 & Respect of students \\
\cline { 2 - 3 } & 0.435 & Ppproved by the Director \\
\cline { 2 - 3 } & 0.380 & position \\
\hline
\end{tabular}


Among the factors of organizational culture, teacher's bad performance and good performance, classroom climate, and student interest factors have been evaluated. The table below shows the results of this analyze.

Table 3. Ranking of organizational culture

\begin{tabular}{|c|c|c|}
\hline Incompatibility Factor & $\begin{array}{c}\text { The relative importance } \\
\text { factors }\end{array}$ & Organizational culture \\
\hline \multirow{3}{*}{0.01} & 0.746 & Teacher's good performance \\
\cline { 2 - 3 } & 0.519 & Teacher's bad performance \\
\cline { 2 - 3 } & 0.480 & Class climate \\
\cline { 2 - 3 } & 0.370 & Students' interest \\
\hline
\end{tabular}

According to the results of the survey among demographic factors preoccupations gain highest score (0.729) and Conscientious was the lowest score (0.334).

Table 4. Ranking of factors affecting individual motivation

\begin{tabular}{|c|c|c|}
\hline Incompatibility Factor & The relative importance factors & Personal factors \\
\hline \multirow{3}{*}{0.017} & 0.729 & Preoccupations \\
\cline { 2 - 3 } & 0.556 & Bonus \\
\cline { 2 - 3 } & 0.375 & Interest to field of education \\
\cline { 2 - 3 } & 0.334 & Conscientious \\
\hline
\end{tabular}

According to below table, it is concluded that incentives effective prioritization of education are:

1 - Group ranking 2 - Science Rank 3 - participation in training classes 4 - discovering the talents. The following table shows the details of the results.

Table 5 - Ranking of factors influencing training factors

\begin{tabular}{|c|c|c|}
\hline Incompatibility Factor & The relative importance factors & Training factors \\
\hline \multirow{3}{*}{0.232} & 0.650 & Group ranking \\
\cline { 2 - 3 } & 0.565 & Science Rank \\
\cline { 2 - 3 } & 0.533 & Participation in training classes \\
\cline { 2 - 3 } & 0.419 & Discovering the talents \\
\hline
\end{tabular}

The results show that among skill factors the highest score is for work outside the home (0.829) and Mastery of the subject got the lowest score (0.581). The following table indicates the results. 
International Journal of Managing Value and Supply Chains (IJMVSC) Vol.5, No. 1, March 2014

Table 6. Ranking of skill factors

\begin{tabular}{|c|c|c|}
\hline Incompatibility Factor & The relative importance factors & Skill factors \\
\hline \multirow{3}{*}{0.009} & 0.829 & work outside the home \\
\cline { 2 - 3 } & 0.651 & experience \\
\cline { 2 - 3 } & 0.581 & Mastery of the subject \\
\hline
\end{tabular}

The following tables show ranking of competition factors.

Table 7. Rating competitive factors affecting motivation

\begin{tabular}{|c|c|c|}
\hline Incompatibility Factor & The relative importance factors & Competition factors \\
\hline 0.00 & 0.748 & $\begin{array}{c}\text { Competition with other } \\
\text { teachers in the field }\end{array}$ \\
\cline { 2 - 3 } & 0.688 & $\begin{array}{c}\text { Teachers compete with the } \\
\text { same majors }\end{array}$ \\
\hline
\end{tabular}

\section{CONCLUSION}

Individual characteristic of the employees' motivation is an important factor [21]. It can be seen in the results that teachers' preoccupations and psychological factors is the most important factor. Thus it can be said reducing the psychological preoccupations can be effective in motivating employees. If the corporate cultures develop and participation in the Promotion, it will also improve job motivation [5]. In this study the most important aspect of organizational performance is well known as a good performance of the teacher. The study of Malmir (2009) about the social relations, the ability to communicate with others has identified as the most important factor to improving productivity [14]. In this study, obtaining reputation is accounted as the highest score in the field of social interaction. Ostvar research (2003) and Keshtkaran (2006) also confirmed the results of this study $[10,15]$. The results show that the degree of competition between teachers of non same filed is more important than competition between teachers in the same field. Working outside the home is the most important motivational factors. Education is an important factor in motivating of staff [7]. Based on the present study team rankings has been identified the most important factors of training. According to this it is recommended greater investment on teachers' training. 
International Journal of Managing Value and Supply Chains (IJMVSC) Vol.5, No. 1, March 2014

\section{REFERENCES}

[1] Ajhei, J., Khodapanahi, M. K., Fathi Ashtiani, A., Sabeti, A., Ghanbari, S., Seyyed Mousavi, P. S., (2009), Interaction between personality and learning styles and motivation in job performance, Journal of Olume Raftari, Vol. 3, No. 4, pp. 301-310

[2] Akhundi Bunab, H. A., Mosavi Shojai, Z., Pirkhaefi, A. R., Mehdipour Moghaddam, M., (2011), The relationship between locus of control managers motivate employees, Islamic Azad University, East Azerbaijan Province, 89-88 years, Journal of Farasoye Modiriat, Vol. 55, No. 17, pp. 33-52

[3] Bakhtiari, A., Godarzi, M., Hamidi, M., Ghorbani, M. H., (2009), Motivational - health factors and physical education experts from universities, government job burnout Tehran Journal of Modiriate varzeshi, No. 3, pp. 135-150

[4] Farhangi, A. A., Rastegar, A. A., (2006), Presentation and explanation-based incentive model of spirituality staff, Journal of Shahed University, Vol. 13, No. 20

[5] Gholami Hiedarabadi, Z., (2011), The relationship between components of organizational culture and motivation and burnout in Tehran Advisors, Journal of Counseling and Psychotherapy, Vol. 2, No. 7, pp. 103-121

[6] Güngör pınar, The Relationship Between Reward Management System And Employee Performance With The Mediating Role Of Motivation : A Quantitative Study On Global Banks, Procedia Social And Behavioral Sciences, 24(2011) pp.1510-1520

[7] Habibipour, B., Vanaki, Z., Hajizadeh, E., (2009), The effect of goal setting theory on job motivation by nurse managers, Journal of Parastari Iran, Vol. 22, No. 57, pp. 67-76

[8] Hong Jon-Chao, Yang Sung-De, Wang Li-Jung, Chiou En-Fu, Sun Fan-Yin, Huang Tsui-Lan, Impact of employee benefits on work motivation and productivity, The International Journal of Career Management, Volume7, Number6, 1995, pp.10-14

[9] Kajbaf, M. B., Pourkazem, T., (2005), Staff and supervisors' views of the National Iranian Oil Company: motivational factors and its relationship with job satisfaction, Journal of Cognitive Science, Vol. 7, No. 1, pp. 67-73

[10] Keshtkaran, A., Kharazmi, E., Youssefi, S., (2006), motivational needs of nurses in university hospitals based on Maslow's hierarchy of needs (2006), Journal of Modiriate Salamat, Vol. 9, No. 24, pp. $45-50$

[11] Khademi, Z., Fakhrzad, M., Akrami, M. K., (2010), prioritize the factors motivating staff to increase productivity (Case Study: Gulf Oil Products Distribution Company), Journal of management and Human Resource Management in the Oil Industry Vol. 4, No. 13, pp. 85-104

[12] Lourdes Machado, Meira Soares Virgilio, Brites Rui, Brites Ferreira Jose, Maria Rocha Gouveia Odilia, A look to academics job satisfaction and motivation in Portuguese higher education institutions, Procedia Social and Behavioral Sciences, 29 (2011), pp.1715-1724

[13] Mahmoudi, H., Ebrahimian, A., Soleymani, M., Ebadi, A., Hafezi, S., Feizi, F., Sadeghi Sherme, M., (2007), Factors motivating nurses in Special parts, Journal of Olome Raftari, Vol. 1, No. 2, pp. $171-178$

[14] Malmir, A., (2009), Ranking Factors affecting labor productivity using the AHP and TOPSIS, MA Thesis

[15] Ostvar, R., Mousavi, A. M., Ghafarian Shirazi, H. R., Abbasi Moghaddam, M.A., (2003), Factors influencing employee motivation, staff and administrators from the perspective of medical science, Journal of Armaghane Danesh, Vol. 8, No. 31, pp. 21-26 
International Journal of Managing Value and Supply Chains (IJMVSC) Vol.5, No. 1, March 2014

[16] Pourhadi, S., Kamali, M., Khalesi, N., Fahimi Malahat, A., (2009), Determine the motivational potential of jobs Rehabilitation in welfare centers in Tehran on the basis of potential motivation, Journal of modiriate Salamat, Vol. 2, No. 37, pp. 57-64

[17] Radafshar, Z., Hosseini Tashnizi, S., Solati, S. M., Naderi, N., Mahbobi, A., (2010), Motivational Factors affecting retention of faculty employed in Hormozgan University of Medical Sciences in 1986, Medical Journal of Hormozgan, Vol. 14, No. 3, pp. 164-166

[18] Rahimic Zijada, Resic Emina, Kozo Amra, Determining the Level of Management Competences in the Process of Employee Motivation, Procedia-Social and Behavioral Sciences, 41 (2012), pp. $535-543$

[19] Rao Prasada, Motivation model for improving productivity in a Manufacturing unit - a success story, International Journal of Productivity and Performance Management, Vol.55, No.5, 2006, pp.430-436

[20] Seyyed Ameri, M. H., (2009), Explaining the relation between participative management as an effective method of employee motivation and physical education offices in West Azerbaijan, Journal of Modiriate Varzeshi, Vol. 1, pp. 5-7

[21] Shafizadeh, A., (2002), Job Motivation Factors of Physical Education Teachers, Journal of Harakat, No. 14, pp. 53-67

[22] Tohidi Hamid, Jabbari Mohammad Mehdi, Role of human aspects in project management, Procedia-Social and Behavioral Sciences, 31 (2012), pp. 837-840

[23] W. H. NG. Thomas, L. Jorensen, T. Eby Lillian, Locus of control at work: a meta-analysis, Journal of organizational Behavior, 27, pp. 1057-1087, (2006)

[24] Zhao Bin, Learning from errors: The role of context, emotion, and personality, Journal of organizational Behavior, 32, pp. 435-463, (2011) 